\title{
Adaptive Management and Community Reaction: The Activities of Coastal Action Groups within the Shoreline Management Process in England.
}

\author{
Taye Famuditi*, Malcolm Bray, Jonathan Potts, Brian Baily and Rob Inkpen \\ Department of Geography, University of Portsmouth, Buckingham Building, Lion Terrace, Portsmouth, \\ PO1 3HE, United Kingdom
}

\begin{abstract}
Changes in UK government coastal and flooding policies in the last twenty-five years, have resulted in a reappraisal of all coastal defence schemes with a focus on a strategic analysis to ensure that all schemes provided the greatest net benefit. This strategy and the emphasis on adaptive management, particularly in the second wave of shoreline management plans (SMPs), provoked a reaction from local communities who felt their voice was largely being ignored as they became aware of SMP policies that increased their perceived risks but did not offer appropriate compensation. The formation of Coastal Action Groups (CAGs), has been a key community response and enabled diverse communities to feel that they can collectively participate in the ongoing planning process. Using a combination of questionnaire surveys and semi-structured interviews, this paper analyses the nature and effectiveness of CAGs. Although initially formed as opposition groups, the shared ideology of CAG members has resulted in the character of these groups evolving to units that embrace a broader range of social justice issues. It is argued that well led, well-supported, well-resourced and tactically astute CAGs have tended to be the most effective pressure groups. In reality however, CAGs have had relatively limited effects in changing the decisions of local SMPs, but have had great impacts in challenging the concept of meaningful public engagement in the coastal planning process, ultimately leading to more participatory approaches.
\end{abstract}

Key words: Coastal Action Groups; participatory approach; stakeholder engagement; shoreline management; decision-maker, England.

\section{Introduction}

In the first decade of the 21st century, the UK Government approach towards coastal flooding and erosion transformed from a coastal defence doctrine to one of flood and coastal erosion risk management guided by detailed considerations of economic and environmental sustainability [1,2]. It involved allowances for giving up land to make space for water and prioritisation of resources for defences and management interventions at locations that would generate most benefit $[3,4]$. Implementation of this change of approach was undertaken by setting strategic coastal defence options for defined local coastal units within Shoreline Management Plans (SMPs) covering England and Wales over the periods 1995-99 and 2006$2011[5,6]$. Those periods represent the preparation phases for the first generation of plans and the subsequent major update of each some 10 years later. Within each plan there was a review of the options to hold, advance or retreat a line of defence or to do nothing for every shoreline frontage. A preferred option was selected to cover future planning periods 20, 50 and 94 years ahead based on a variety of evidence and evaluations [7]. Following publication of each plan, further studies and, where necessary, strategies would be undertaken to implement the preferred options. It led to reappraisals of all existing defences and in some cases changes in the nature of future defences including reduction of defences and switches to limited or non- 
intervention. These changes in practice have caused profound implications for significant stretches of the coastline and its inhabitants [8,9]. Its more strategic approach to flood and coastal erosion risk management shifts a greater responsibility towards coastal communities especially in situations where defence policies alter and there becomes a need to adapt to coastal changes rather than defending against them $[4,6]$. These issues became exacerbated whenever specific plans proposed to cease to maintain or withdraw existing local defences leading to anxieties within communities about impacts [10-12].

Communities reacted quickly and started to form residents' groups to express their concerns and seek solutions. In river and estuarine situations where relatively modest engineering approaches could be feasible, direct action self-help groups (DASH) developed that sought to create or maintain their own local flood defences [13]. By contrast, on exposed coasts and eroding cliff coasts where a higher level of engineering was likely to be required to maintain the status quo the groups tended to reject initially the notion of adapting to coastal changes and instead demanded changes in local policy accompanied by demands for social justice and compensation [14,15]. It is these groups that are the subject of this paper and we refer to them as Coastal Action Groups (CAGs), because collectively they take actions to achieve their aims and they demand actions from those with management responsibilities. This paper provides the first critical evaluation of the formation, function and achievements of these groups.

Although previous research has investigated community engagement, public participation, and stakeholder dialogue in coastal management initiatives in England (including: [10,15-25]), none has focused specifically on action groups collectively, although Tebboth [26] undertook a "Frame Theory" based analysis of one single group located at Happisburgh. An "Action Group" is only one of a series of terms that have been used to describe a body formed to campaign on a particular issue [27]. Other terms typical within the wider umbrella of environmental groups include "Pressure Group”, “Lobby Group”, “Interest Group”, “Residents Group" and "Protest Group" [28-31]. None of these terms alone was considered suitable to define the group approaches and activities that the study has investigated. CAGs represent an action-led, single issue-orientated reaction to concerns and policy changes at the coast whereas other types of "Groups" may act more as communication and discussion forums or even as voluntary practitioners in the case of DASH groups. Thus, the original definition of CAGs applied in this study is deliberately broad, to be inclusive of the groups under consideration, yet still enable distinction from other types of "Groups." As such the definition of a CAG reads as:

A group of voluntary bodies and stakeholders which seeks as its prime aim to influence actively the decision-making process of management authorities in an attempt to secure social justice in shoreline governance.

CAGs initially intended simply to represent community concerns on specific issues, but to a variable extent they did have secondary aims such as to: (i) raise community awareness of coastal issues; (ii) develop a degree of consensus on critical issues; and, (iii) generate a "voice" that is difficult for decision-makers to ignore. CAGs are not unique in terms of community-led action within the wider area of environmental issues and differences between groups according to how they pursue their aims can enable a functional classification. Kempton et al. [32] identified three different types of environmental groups: oppositional, single-issue groups; environmental justice groups; and, radical groups. Although most CAGs started as single issue groups it quickly became obvious that some had diversified so that it was useful to apply this classification in this paper's methodology. 


\section{Research Methodology}

Desk based interrogation and enquiries within coastal networks were undertaken to find local and environmental interest groups in existence in England, to determine which groups were relevant to this study and to provide a 'sampling frame' from which case studies could be selected. In early 2012 at the beginning of this research [33] up to 20 prominent communitybased groups were identified in England and Wales. From 1998 onwards, there appeared to be a significant increase in the number of CAGs in England linked to the aforementioned changes in flood and erosion risk management and also to increased community demand for genuine participation in decision-making. Although the groups differed considerably in their specific aims, composition, and mode of operation according to the issues at their geographical location they formed a valuable initial sample.

Subsequently, the online presence of the CAGs was investigated (10 of the CAGs maintained their own websites at the time of survey) to collect evidence of each group's activities. Each group's coordinator was contacted in order to find out more details about each group, their members and their aims. Care was taken to provide full details of the research and to engage coordinators over a period of time at mutually convenient times to gain their trust and willingness to co-operate. Based on the information generated, case study groups were selected by applying the following criteria: 1) composed of or run by volunteer participants; 2) involved in shoreline management activities; 3) function as a CAG and not as a DASH; and, 4) associated with political activity such as lobbying government and/or raising public support for their perspective on issues. These criteria were important to separate CAGs from other noncampaigning and less confrontational types such a DASH. On this basis, 12 CAGs were identified for further study (Figure 1 and Table 1) and the co-ordinators of each agreed to be recruited to the study.

A questionnaire survey of 10 members per CAG was undertaken to explore personal motivations, knowledge, attitudes and perceptions within each group. The questionnaire mainly involved succinct multi-choice questions, but some open-ended questions were also included to collect contextual information. It was piloted initially using small samples of respondents including those with and without familiarity to coastal issues enabling it to be refined and made meaningful to the CAG members. Participants were recruited directly by group co-ordinators from their membership pools using participant invitations, information sheets and questionnaires supplied by the researcher. This exercise generated 78 responses from the 100 questionnaires distributed. The Selsey (SOS) and Ham (HRG) groups had disbanded in 2011 so no member questionnaires could be complete; however, their former coordinators remained active within a multi-stakeholder advisory group so that they could still be interviewed about their respective CAGs. Four responses were received from Pagham (SPB), but otherwise between seven and ten responses were received from the other nine groups. The high response rates are attributed to the tactic of recruiting and guiding each coordinator to facilitate the questionnaire. That way, the group members being recruited gained a degree of trust in the questionnaire and were more likely to complete it. A potential drawback of this approach is that considerable time was sometimes required to gain the trust of CAG coordinators. It was also noted that faster and more complete survey returns were received from those groups that met regularly, whereas those with irregular or less frequent meetings responded more slowly. 
Face to face semi-structured interviews were undertaken with the present and former coordinators of each of the 12 CAGs. To gain their trust and candour, coordinators were sent advance copies of the schedule of questions and were encouraged to choose their preferred venue and time at which to meet. Care was taken to issue meeting reminders and to offer rescheduling whenever meetings were postponed by the interviewee. Although this procedure required considerable patience and time it was successful in facilitating substantive interviews with each CAG coordinator (average duration 79 minutes each). A further benefit was that almost all coordinators also offered a short tour of their communities to illustrate the sites of perceived flood and/or erosion risk. Interview questions focussed on five distinct areas: (i) formation, mode of operation and notable achievements of the group; (ii) understanding of social justice; (iii) relationship of the CAG with the wider local community; (iv) role of community participation in shoreline management decision-making; and, (v) future aims and aspirations. Opportunities were extended wherever possible to allow interviewees to elaborate points and provide anecdotes freely and structuring was only applied to ensure key areas were covered consistently between interviews. Interviews were also conducted with professional practitioners in shoreline management involving four interviews with relevant officers from the Environment Agency and coastal local authorities and two with consultants. The aim in each case was to obtain alternative perspectives on the roles and impacts of CAGs from those involved in devising, applying and implementing coastal change adaptation policies.

Each interview completed was transcribed and sent to the interviewee for checking. The transcribed transcripts were coded and stored using Atlas.ti (qualitative data analysis and research software). To streamline the data analysis process, Hermeneutic Unit was created within the Atlas.ti, this contained all the Primary Data from the interviews and questionnaires. An inductive approach (bottom-up), organised in 3 sequential stages - open, axial and selective coding was used in order to code into different categories. Direct quotations from the transcribed interviews were also coded accurately to maintain the anonymity of the respondents and presented in italics. 


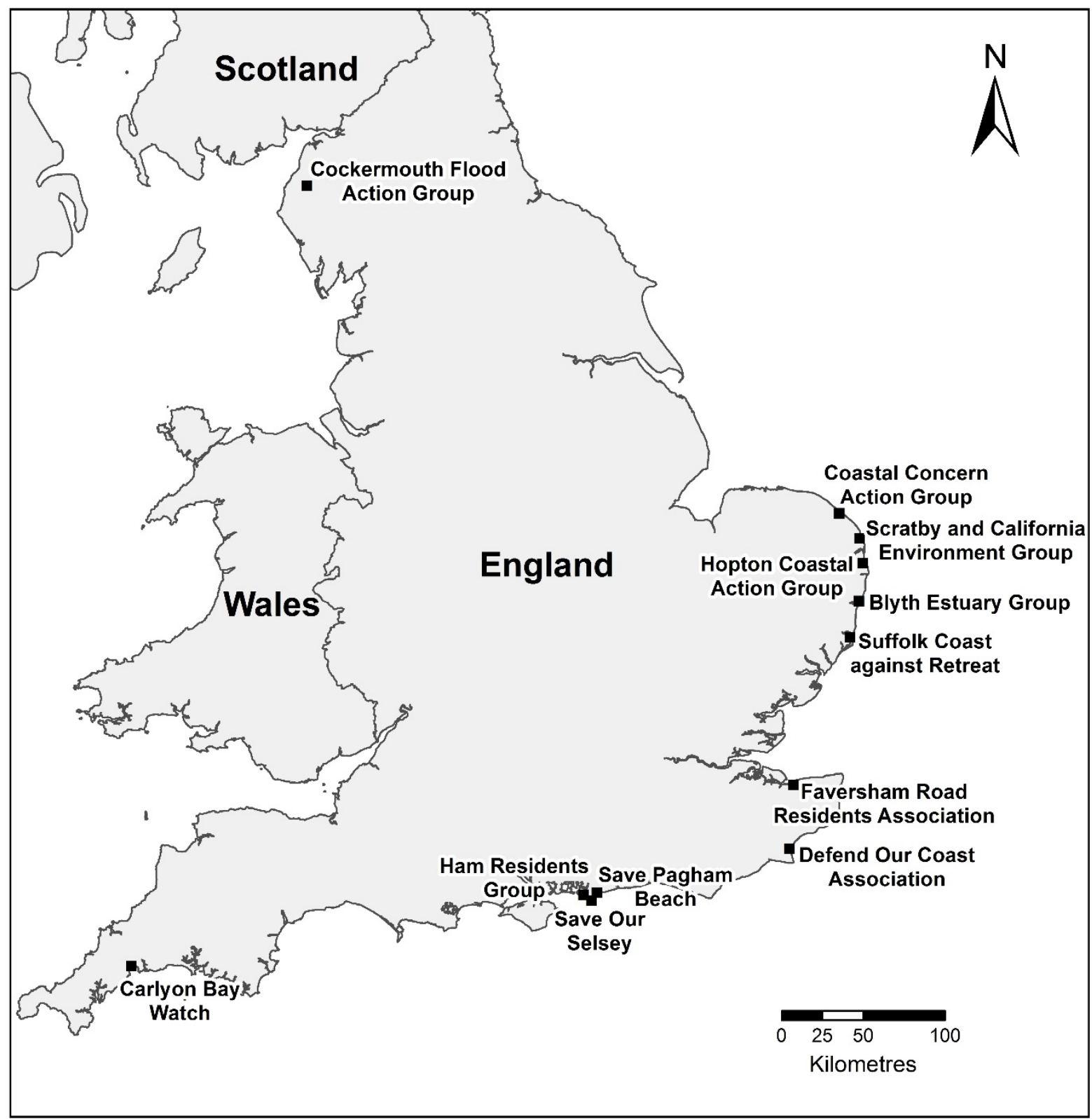

Fig. 1. Location of CAGs in England. Note their concentration in the south and south east where well populated low-lying and/or soft rock shorelines predominate leading to the most extensive flood and erosion risk issues. 
Table 1

CAGs identified for study within this paper. * denotes a group that has dissolved, but with some members still active within an advisory group.

\begin{tabular}{|c|c|c|c|}
\hline Group Names & $\begin{array}{c}\text { Group Type } \\
{[32]}\end{array}$ & Core Interests & $\begin{array}{c}\text { Date } \\
\text { Established }\end{array}$ \\
\hline $\begin{array}{l}\text { Coastal Concern } \\
\text { Action Group } \\
\text { (CCAG) }\end{array}$ & $\begin{array}{l}\text { Oppositional, } \\
\text { single-issue }\end{array}$ & $\begin{array}{l}\text { Oppose the local SMP shoreline management option } \\
\text { at Happisburgh and demand compensation and } \\
\text { improved community consultation and participation. }\end{array}$ & 1998 \\
\hline $\begin{array}{l}\text { Hopton Coastal } \\
\text { Action Group } \\
\text { (HCAG) }\end{array}$ & $\begin{array}{l}\text { Oppositional, } \\
\text { single-issue }\end{array}$ & $\begin{array}{l}\text { Against the SMP decision of "No active } \\
\text { intervention" for Hopton. }\end{array}$ & 2000 \\
\hline $\begin{array}{l}\text { Carlyon Bay } \\
\text { Watch (CBW) }\end{array}$ & $\begin{array}{l}\text { Oppositional, } \\
\text { single-issue }\end{array}$ & $\begin{array}{l}\text { Oppose development at Carlyon Bay under banner } \\
\text { headline “Let’s Get Our Beach Back.” }\end{array}$ & 2004 \\
\hline $\begin{array}{l}\text { Suffolk Coast } \\
\text { Against Retreat } \\
\text { (SCAR) }\end{array}$ & $\begin{array}{l}\text { Oppositional, } \\
\text { single-issue }\end{array}$ & $\begin{array}{l}\text { Continuous maintenance of Suffolk coastline, tidal } \\
\text { river and surrounding land area by 'Holding the line' } \\
\text { using coastal defences. }\end{array}$ & 2005 \\
\hline $\begin{array}{l}\text { Scratby and } \\
\text { California } \\
\text { Environment } \\
\text { Group (SCEG) }\end{array}$ & $\begin{array}{l}\text { Environmental } \\
\text { justice }\end{array}$ & $\begin{array}{l}\text { To campaign to protect and conserve the beaches, } \\
\text { cliffs, coastline and land at Scratby and California, } \\
\text { using coastal defences. }\end{array}$ & 2005 \\
\hline $\begin{array}{l}\text { Blyth Estuary } \\
\text { Group (BEG) }\end{array}$ & $\begin{array}{l}\text { Oppositional, } \\
\text { single-issue }\end{array}$ & $\begin{array}{l}\text { To oppose the } 2005 \text { Blyth Estuary Strategy and } \\
\text { challenge the managed realignment proposals by the } \\
\text { Environment Agency (EA). }\end{array}$ & 2006 \\
\hline $\begin{array}{l}\text { Faversham Road } \\
\text { Residents } \\
\text { Association } \\
\text { (FRRA) }\end{array}$ & $\begin{array}{l}\text { Environmental } \\
\text { justice }\end{array}$ & $\begin{array}{l}\text { Oppose the draft SMP and promote the common } \\
\text { interests of all residents who live in Faversham Road } \\
\text { and the surrounding area. }\end{array}$ & 2007 \\
\hline $\begin{array}{l}\text { Save Our Selsey } \\
\text { (SOS) }\end{array}$ & $\begin{array}{l}\text { Oppositional, } \\
\text { single-issue }\end{array}$ & $\begin{array}{l}\text { Advocate short and long term defence-led strategies } \\
\text { for management of flood and erosion risks along the } \\
\text { Selsey peninsula. }\end{array}$ & $\begin{array}{l}2007- \\
2011^{*}\end{array}$ \\
\hline $\begin{array}{l}\text { Ham Residents } \\
\text { Group (HRG) }\end{array}$ & $\begin{array}{l}\text { Oppositional, } \\
\text { single-issue }\end{array}$ & $\begin{array}{l}\text { To consider and present the views of the Ham } \\
\text { community on the impact of the Coastal Defence } \\
\text { Strategy. }\end{array}$ & $\begin{array}{l}2008- \\
2011^{*}\end{array}$ \\
\hline $\begin{array}{l}\text { Defend Our } \\
\text { Coast } \\
\text { Association } \\
\text { (DOCA) }\end{array}$ & $\begin{array}{l}\text { Oppositional, } \\
\text { single-issue }\end{array}$ & $\begin{array}{l}\text { Promote sustainable defence of the coastline and } \\
\text { oppose 'managed realignment' policy options. }\end{array}$ & 2008 \\
\hline $\begin{array}{l}\text { Cockermouth } \\
\text { Flood Action } \\
\text { Group (CFAG) }\end{array}$ & $\begin{array}{l}\text { Environmental } \\
\text { justice }\end{array}$ & $\begin{array}{l}\text { To work with the flood risk management authorities } \\
\text { in the local area to achieve reductions to the flood } \\
\text { risk. }\end{array}$ & 2009 \\
\hline $\begin{array}{l}\text { Save Pagham } \\
\text { Beach (SPB) }\end{array}$ & $\begin{array}{l}\text { Oppositional, } \\
\text { single-issue }\end{array}$ & $\begin{array}{l}\text { Promote sustainable management of Pagham Spit to } \\
\text { address problems of erosion at Pagham Beach. }\end{array}$ & 2013 \\
\hline
\end{tabular}




\section{Results and Discussion}

The findings from the questionnaire analysis are compiled, compared and integrated with those from desk studies, field observations and the coordinator and practitioner semi-structured interviews to develop the analyses and discussions below.

\subsection{Formation and Development of Coastal Action Groups}

CCAG formed in 1998 followed by HCAG in 2000 with the remainder of the groups forming over the period 2004 to 2013. In almost all cases groups formed in reaction to specific shoreline management policies formulated within local SMPs. It is notable that group formation coincided much more strongly with publication of the second generation of SMPs (2006-2011) rather than with the first generation of plans (1995-1999). That is thought to be because: (i) unlike second generation SMPs the first generation plans typically recommended relatively few changes to local defences [5,34]; and, (ii) at first stakeholders did not appreciate the local significance of shoreline management policies presented in SMPs that were perceived to be strategic in nature. Only when changes in SMP policies started to be implemented on the ground did local communities take notice and react.

Groups formed because local communities perceived that specific changes in local shoreline defence policies would result in them becoming at increased risk without adequate warning and without a corresponding policy for compensating those affected. One CAG coordinator exemplified this with the following: "It was never my intention to get involved but there was no alternative. They went from 'hold the line' to 'no active intervention' - it changed overnight without any consultation or nothing." Initial attempts to reject or alter proposals were ineffective and local communities felt that whey were not being listened to. CAGs therefore formed both in reaction to these events and also to press for improved participation in decisionmaking in order to seek alternative defence policies. Members joined groups because of broad concern for their local environment, their recreational opportunities and concern for the interests of their community, even though only some had experienced erosion or flood losses themselves or were imminently at risk. When questioned it was explained that many members joined as much out of injustice, solidarity with their neighbours and concern for their community as they did out of worries about personal risk. It was felt by CAG members that they had been treated in an unjust manner that demanded a response to gain social justice.

Analysis of the views expressed suggested that initial concerns about specific local defences and risks to individuals were translated in the minds of CAG members to broader considerations relating to local environment and community as has been reported in other cases of single issue protests (e.g. [35-37]). Furthermore, this situation was exacerbated by ineffective community participation because consultation was offered only when discussing SMP policies within the SMP preparation process and many communities appeared to miss this opportunity e.g. Ballinger and Dodds [7]. Communities therefore did not become aware of decisions until plans to implement policies were publicised leading to the perception amongst the local communities affected that the statutory management authorities were not listening. CAGs gained some further initial momentum from the early candid responses from some coastal managers that CAGs had unrealistic expectations for defences. For their part CAG members expressed a lack of trust in government to provide an adequate solution to their perceived challenges. Views became polarised and CAGs and the management authorities initially became protagonists. 


\subsection{CAG Typology}

CAGs were categorised into three main types of interest: 'Oppositional, single-issue' 'Environmental justice' and 'Radical' according to their aims and modes of operation in a manner similar to that described by Kempton et al. [32]. Groups classified as 'Oppositional, single-issue' groups included those forming in reaction to a specific threat and having a singular focus on solving that problem. The majority of the groups (75\%) in this research described themselves as belonging to this category, however, our view is that most groups diversified to differing extents following their formation. Typically, some have diversified the topics that they react to and voice opinions on topics such as inshore dredging and alternative soft engineering techniques. Many campaign for social justice and compensation as means to address their coastal defence concerns. Some have sought links or alliances with other groups and some have even developed relationships with the statutory authorities that they formerly opposed. Members of the CCAG in 2008 set up an umbrella organisation "National Voice of Coastal Communities" [38] to provide a forum to improve coordination and cooperation between CAGs and act as a focus for national campaigning.

Based on the experiences of Kempton et al. [32], the definition of Environmental justice was expanded slightly to better cover some of the activities reported from the CAGs. 'Environmental justice' groups promote fair distribution of environmental benefits and burdens that can involve campaigning and direct action, but also can include education and collaboration or even partnership or active links with statutory authorities. This expanded definition includes reduction of inequalities by sharing of knowledge and expertise within the local community that can for example include awareness of SMPs decision making, alternative coastal defence techniques and issues such as loss of coastal wetlands, loss of salt marshes, loss of migrating birds, sedimentation, beach conservation and coastal erosion. This group best characterised three of the CAGs investigated, although all of the CAGs had to varying extents evolved towards this category following their formation. None of the respondents in this study described their group as 'Radical'. As one respondent pointed out: 'We are not radicals, we campaign for our rights, rights to be listened to'. Nonetheless the majority of CAGs have campaigned energetically and robustly and some such as CCAG have undertaken political lobbying and active protests.

Using the above classifications, the research identified nine Oppositional, single-issue groups, three Environmental justice groups and no groups that were primarily radical (Figure. 2). However, the groups were more complex than the classification might initially suggest with considerable evolution and diversification through time resulting in difficulties for researchers in classifying groups at the time of the research. By contrast group members were surprisingly consistent amongst themselves in classifying their groups, perhaps because they retained the image of their group at its inception rather than considering its evolution. 


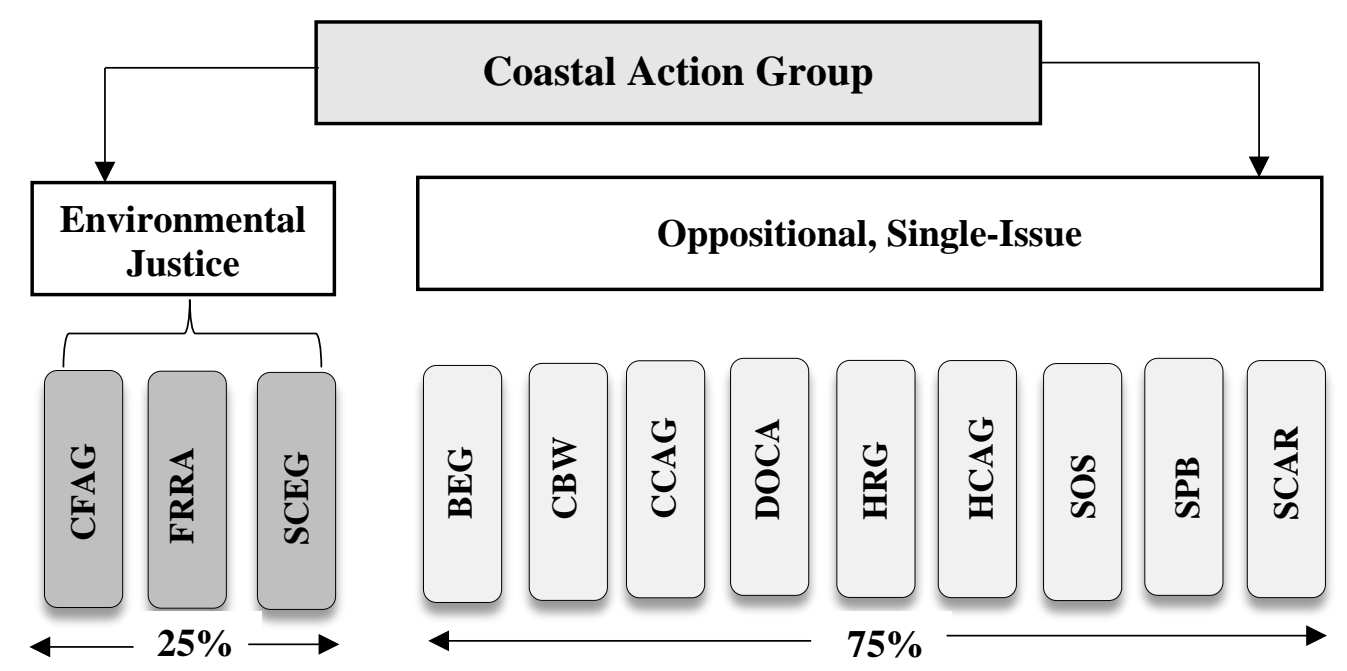

Fig. 2. Classification of CAGs according to the modified method of Kempton et al. [36]

\subsection{Group Composition}

All CAGs were composed of a leader/coordinator and a group of members. A shared ideology [39] is a central feature of CAGs. Their goals, such as a rejection/ modification of management options for instance, could be supported by everyone regardless of social or economic status. As a result, the groups do not usually place any restrictions on membership as they are based on shared attitudes and values. One coordinator recalled: "We had a meeting in the local church hall and the morning after that, the group was formed. Originally I think that they were six, I was brought in a few weeks later because I wrote a bit of an article in the local paper on my reaction and the next thing the guys are knocking on my door saying come and join the group."

All CAGs related to very specific geographic locations and only Suffolk Coast Against Retreat (SCAR) widened their coverage to encompass SE Suffolk estuaries. This meant that membership catchments could be limited and that thinking could potentially be confined by place attachment and place identity [40]. This contrasts with the highly strategic nature of SMP policies that CAGs react to and possibly explains how communities missed the initial SMP consultation opportunities. Arguably, this also became a strength allowing CAGs to help draw communities together and stand their ground against the perception of externally imposed decisions.

Membership information varied considerably between groups with some having formal recruitment, enrolment and subscription procedures supported by a database of member details, some simply maintained lists of names and contact details, whereas others considered any person participating in group meetings and activities as a member. This made it difficult for some groups to be able to accurately monitor their membership numbers. Coordinators quoted membership numbers of between 5 members (SPB) and 1,200 members (SOS). These two groups were perhaps unusual, for SPB were very recently formed and have subsequently increased their membership, whereas SOS was able to recruit from the town of Selsey that has a population of 11,000. Most groups indicated that they had fewer than 100 members and CEW and BEG had fewer than 15 members, whereas CCAG claimed around 300 active members which is equivalent to the adult population of their home village of Happisburgh. 
Larger memberships were considered beneficial for fundraising, lobbying, protesting and for sustaining highly active groups, but nonetheless generated requirements for administration and for regular events to maintain interest and avoid members becoming inactive. Smaller memberships were characterised by higher proportions of active members, but were considered to be highly dependent on the contributions of a few individuals. Furthermore, CAGs with small memberships could be lacking in authority due to uncertainties of the extent to which they represented their community.

CAG Members were almost always local residents, especially homeowners and those engaged with local businesses. Many commented that they felt that they had a "stake in the local community." However, most CAG coordinators acknowledged that many members were "contributors" rather than being fully "active" members with full involvement in their group's activities. Contributing could be through critiques, suggestions for group campaigns, signing petitions or making donations as has been reported from other types of groups (e.g. [41,42]). "Contributors" were nonetheless welcomed by CAGs as they were perceived to form a pool from which future active members could be drawn. One interviewee remarked: "Yes Save Our Selsey had about 1,200 signed up members which were more than 10\% of our population, but I wish that was the number of our active members." Two key factors appeared to influence member activity: (i) retired persons were more likely to be "active" in CAGs as they had available time, whereas younger persons with full time working commitments and a family at home were more likely to be "contributors" due to lack of time; (ii) CCAG demonstrated that energetic leadership, good communication and a creative programme of events could help to generate a large number and high proportion of "active” members.

\subsection{Campaign Methods and Tactics}

The three most frequent campaign priorities of CAGs were to: (i) challenge specific local shoreline management policies; (ii) secure greater participation in decision making; and, (iii) mobilise the local community and other stakeholders to meet and discuss solutions to shoreline management issues. Collectively, these priorities can be labelled as demands for environmental and social justice such that CAGs form an interesting example of the contention by Agyeman and Evans [43] that "environmental justice is moving from the margins to the mainstream in Britain"

A range of actions have been used by CAGs in their campaigns; such as writing letters of protest, offering interviews to local media, meeting and lobbying local politicians, organising meetings to air views and recruit members, establishing a simple group website, organising petitions and producing and wearing badges, t-shirts etc. Such activities are deemed part of the conventional political process [44] and are all relatively low-cost in terms of the time and effort required to perform them although skills are required to do them well. Conversely, taking part in high-cost forms of campaigns such as running a dedicated website as a campaign tool, meeting and lobbying national politicians, engaging with national media, undertaking a public demonstration [45] are less common and require considerable skill to be successful. Nonetheless, all of these techniques have been applied by CAGs which is testimony to the determination of those groups and their capabilities in harnessing the latent skills of their members.

Examples of "high cost" actions are provided by CCAG who operated a regularly updated and information rich campaigning website up to 2012, it also hosted visits by local and national politicians, organised a visit to Brussels to lobby European Union officials and its members 
undertook a coordinated demonstration to lobby Government at a key parliamentary adjournment debate at the Houses of Parliament, Westminster in 2005. Interestingly, very few CAG members disclosed in questionnaires or interviews that they had taken part in any direct or unconventional actions in support of their campaigns and all stated that they preferred conventional discourse through power of argument rather than active confrontation. This was clearly explained by one of the coordinators: "We are not radicals; we are not here to throw stones at DEFRA or the Environment Agency representatives" It should be noted that those authorities are those responsible for development and implementation of SMPs so they become the foci of blame for the CAGs.

In order to achieve specific campaign aims, a variety of tactics were used by CAGs to lobby management authorities directly, communicate their viewpoints to the general public and to lobby politicians and other stakeholders in the hope that they could bring pressure to bear on the management authorities when bringing their cause and ideas to the attention of the management authorities. Three areas of media campaign activity were identified as being prevalent across most campaigns as follows: (i) networking through writing letters, emails and contact through the internet; (ii) organising public meetings and publicity events and inviting news media to attend; (iii) contact through newsletters; and, (iv) the use of campaign websites [46]. Several group coordinators indicated that the experience gained from writing formal letters, briefing the media, hosting visiting politicians, attending meetings, conferences and other events to network helped CAG members generate the confidence to engage in the campaign strategies they employed and thus facilitated community participation as has been observed elsewhere by Gil de Zúñiga et al [47].

The use of websites has now become a familiar campaign tactic used by action groups to gain publicity [48-51]. The websites play an important role in communicating with the majority of the groups [52]. In particular, this has provided opportunities to disseminate information and encourage others to join their campaign, with some groups just having a single web page, whilst others have many pages and sections. A number of CAGs use their websites to seek donations and pledges from the public. Another growing trend in campaign tactics is the use of social networking sites like Facebook, Instagram, Twitter and videos on YouTube [53-55]. In some cases the groups assigned one of its members to manage their social media site, which then permits members of the community to communicate and comment on issues affecting their shoreline. Jordan and Maloney [56] and Bosso [57]; argued that communication exchange (interaction and information sharing) often determines the effectiveness of environmental groups. In terms of communicating with the public, almost three-quarters of the groups produce some form of publication such as newsletters, leaflets or flyers. These are used to communicate a range of information about the groups, which include aims, activities, membership, benefits and to keep members up to date with shoreline management issues and possible solutions.

\subsection{Measuring Group Effectiveness}

The effectiveness of CAGs involves considerations firstly of how effectively they have operated as pressure groups and secondly of the extent to which they have been able to influence shoreline management. CAGs that are well led, well supported, well resourced, communicate well and are tactically astute are more likely to be effective in their campaigns. Although different CAGs demonstrated different strengths and weaknesses a qualitative assessment of CAG performance based on the criteria above suggested that most CAGs broadly met or exceeded those required (Table 2). A possible exception concerned the extent to which CAGs represented the views of their local community. In cases where membership accounted 
for a substantial proportion of the local population e.g. SOS and CCAG there could be no doubt on this issue, but for the other CAGs that had small memberships it remained uncertain. All group members and most coordinators questioned felt that their groups were representative of the views of their local communities. The professional practitioners for their part also expressed the view that they thought that the CAGs that they had dealt with were representative of their communities.

Table 2

Estimation of CAG operational effectiveness

\begin{tabular}{|c|c|c|}
\hline $\begin{array}{c}\text { Criteria for measurement of } \\
\text { success }\end{array}$ & Group classification & $\begin{array}{c}\text { Number of CAGs } \\
\text { achieving criterion }\end{array}$ \\
\hline \multirow{2}{*}{ Active campaign leadership } & Oppositional single-issue & 7 \\
\cline { 2 - 3 } & Environmental justice & 3 \\
\hline \multirow{2}{*}{ Representative of Community } & Oppositional single-issue & $2 ?$ \\
\cline { 2 - 3 } & Environmental justice & $?$ \\
\hline \multirow{2}{*}{ Adequate funding } & Oppositional single-issue & 6 \\
\cline { 2 - 3 } & Environmental justice & 3 \\
\hline \multirow{2}{*}{ Strong link and networking } & Oppositional single-issue & 5 \\
\cline { 2 - 3 } & Environmental justice & 3 \\
\hline \multirow{2}{*}{ Effective campaign tactics } & Oppositional single-issue & 7 \\
\cline { 2 - 3 } & Environmental justice & 3 \\
\hline
\end{tabular}

Most CAGs in this study have committed, knowledgeable, authoritative and in many cases energetic leaders who take up active roles in their campaigns. Their local connection, single issue focus and willingness to use direct tactics appears to empower them to act more decisively and use their positions more effectively than leaders of other types of groups that adopt 'softer' and 'diplomatic' approaches. Therefore, a well-led CAG has the capacity to achieve a stronger position in negotiations with management authorities and other stakeholders. A potential downside of this is that CAGs can be very dependent on securing a strong and effective leader. Notwithstanding these issues a number of members claimed that the simple act of people coming together within a CAG to meet, work, lobby and protest together on an issue of mutual concern reinforced their sense of community and was broadly beneficial to those who experienced it.

All CAGs are small, non-profit organisations with limited capacities so that the majority of coordinators interviewed felt that obtaining funding was difficult and this therefore confined their campaigns. However, most groups were highly resourceful and their members would give freely of their time and make donations. Some CAGs employed innovative and low-budget methods to disseminate their messages and raise funds enabling them to operate. For example, one of the group coordinators recounted an unusual fund raising approach to support their campaigns. He commented that "to raise money at all what we do is we collect scrap metals. Neighbours and members tell me if they've got scrap metals and I arrange with another member who has a truck to collect them. We actually got a licence to collect scrap metals and that funds our cause." In 2004 CCAG started the "Buy A Rock For Happisburgh" campaign and its members created a charity called Coastal Concern Ltd and were successful in raising significant funds that contributed towards construction of a new protective rock revetment on their frontage in 2008. Funding remains an issue with most CAGs but all have found ways to operate effectively with limited funds. 
Most CAGs are linked to other groups or organisations in some way either through direct association or by loosely working together. For example, some of the groups in this study had mutual links with one another while others are affiliated with the National Voice of Coastal Communities (NVCC). The NVCC came into being during 2008 as a website for community action groups and individuals campaigning against government policies on shoreline management, and as a focus of national campaigning [38]. Then, in 2009, it was reconfigured as a membership organisation and aimed to act as a conduit between relevant coastal communities and central government [38]. The founder of NVCC explained the reasons for its formation that "it was intended to be a vehicle for communities to hook onto and stand together. Central government couldn't pick one community off. The whole thinking of NVCC was you hurt one coastal community, you hurt all other coastal communities in the country. Together we demand a socially just way forward."

\subsection{Impacts on Shoreline Management Processes}

The intervention of CAGs in shoreline management planning caused interruption, reconsideration and delays in confirming and implementing shoreline management policies. However, very few preferred shoreline management options were overturned as a result of a CAG intervention. Although SMPs should in theory be responsive to consultees due to specific guidance provisions for second generation SMPs [58], this was often compromised by failure to achieve an informed and representative participation. Managers explained that it was often difficult to interest communities and elicit opinions concerning SMP decisions due to their strategic nature and complex methodology. Furthermore, it was noted that consultation operated on a project to project basis, making it difficult to facilitate long-term engagement and consequential community education on strategic issues. As a result, communities often did not learn of the full implications of SMP policy changes until plans or schemes to implement decisions were publicised months or years after SMPs had been agreed. Communities therefore "missed" the opportunity to engage with managers on the key strategic decisions and sought redress via CAG formation and campaigning. One CAG co-ordinator commented "They haven't asked the right questions as far as the people who will be affected are concerned, in terms of stakeholder meetings, consultations or how you can genuinely influence what happens. Often it looks like the decisions were made before the consultation. The consultation was then worked out with the questions in order to get the answers they want."

Since SMP decisions had already been drafted, consulted upon and agreed before most CAGs had formed it was difficult and perhaps unrealistic for CAGs to overturn them. Nonetheless, CAG involvement did prompt significant alterations in the manner in which changes in policy were consulted upon and implemented. For example, DEFRA became aware that policy changes which exposed communities to increased risks would require mechanisms to help them to adapt to change. An $£ 11$ million Coastal Change Pathfinder project was funded by DEFRA involving fifteen different case study approaches to coastal change from which best practices were identified [59]. It included a project at Happisburgh that successfully brokered community acceptable ways of introducing land use changes to accommodate coastal changes [14].

Coastal managers were remarkably positive about the benefits of CAG involvement highlighting the value of local knowledge and perspectives at early stages of participation in order to reduce the risks of conflicts later in decision-making. Even when managers recounted adversarial encounters with CAGs they reported that a dialogue developed over time that created opportunities for further co-operation. For example, intervention of SOS and HRG 
within the consultation on the Selsey Pagham to East Head coastal defence strategy [60] led to enhanced engagement, some alterations of options and ultimately led to the disbanding of both of those CAGs. In their place grew the Medmerry Stakeholders Advisory Group (MStAG) which included former CAG members, other community and landowner representatives, and the Environment Agency and local authorities [60]. It enabled participation in decision-making and has resulted in good co-operation between the community and managers. Advisory groups of this type are seen by all concerned as key facilitators of the types of coastal change and community adaptation that will be required for the future and which are slowly developing around the coast of England e.g. Creed et al. [61]. The role of CAGs in prompting key parts of this process should be acknowledged.

\section{Conclusions}

This paper has introduced the role and function of CAGs and analysed their importance in achieving specific campaign objectives and their significant influence in relation to wider shoreline management policy and practice. Identifying the diversity of CAGs, their influence and their various typologies provides an important means of categorising and better understanding the groups. The typology of Kempton et al. [32] only proved partially helpful in the classifications. Critically this study found that although CAGs typically form with a tight aim to pursue and oppose the single issue that led to their formation they tend to evolve through time to pursue a more diverse set of objectives. Although no CAG fully achieved their initial aims in overturning management decisions, many did achieve broader and longer-lasting benefits in highlighting shortcomings in community engagement and in implementing changes in coastal defence options.

The notion that local communities can be empowered through participation has spread and has become understood by local managers and acknowledged by strategic authorities e.g. DEFRA Coastal Change Pathfinder project. Of key importance are that individuals with various perspectives and experiences who are committed and concerned with protecting some aspect of the environment have formed and driven forward the CAGs. These groups are influential vehicles for local communities' participation, and clearly provided an effective mechanism for public participation in shoreline decision-making processes. Interestingly these benefits emerged out of conflicts between the management authorities and the local communities over changes in policy. Other key reasons for the formation of CAGs found by this study are to educate and raise public awareness, and to seek formal recognition and environmental justice for their communities. In some cases, CAGs have even had the effect of reinforcing a sense of community in their localities.

A significant finding during the course of this research was that past communications between the management authorities and the local communities were problematic. Often there was a mismatch between expectation and provision and the activities of CAGs highlighted this. Critically, in the majority of instances, CAGs developed their objectives based on the concept of participation covering wider issues. They could transform from 'active campaigners' to participatory stakeholders once their objectives were met sometimes resulting in the dissolution of the CAG and the formation of an advisory group. Typically, those advisory groups would include elements of former CAGs that would work alongside management authorities and participate actively in making decisions affecting their local communities. 
CAGs are not only able to protect communities' interests effectively at the local level, some also play a part at the regional level. Since local communities have a diverse range of shoreline management concerns, a significant number of the individuals join more than one group. This study found evidence to suggest that CAGs frequently have overlapping memberships. Additionally, many people who are members of smaller local groups are also members of the larger organisations. Consequently, at both the local and regional levels there are extensive networks of relations, both formal and informal, across the environmental spectrum. On a formal level groups cooperate via direct funding, campaigning alliances and information exchange. For example, the National Voice of Coastal Communities (NVCC) has often collaborated with Coastal Concern Action Group, Defend Our Coast Association, Save Our Selsey, Faversham Road Resident Association and Scratby and California Environment Group. CAGs are usually willing to cooperate with each other because in practice their goals and beliefs are frequently not as far apart as it would appear. Although it is possible to detect differences between the groups' interests, this does not necessarily mean they are pulling in different directions in terms of their campaign objectives.

The findings in this paper imply that decision-making is a dynamic process where dialogue and trust are important influential factors, and where all stakeholders in principle aim at shared decision-making. Beierle and Cayford [62] argued that whenever public participation is limited, conflicts will usually occur. In order to effectively solve the issues relating to community participation, attention must be paid to differences in societal viewpoints, interests and concerns [63]. A divulgence of factual information on the management of the shoreline to the wider community is essential [64]. Importantly, public participation in decision-making processes must be encouraged. This in many cases will lead to a greater chance of achieving a consensus [65,66]. It can be argued that CAGs have developed value and influence by highlighting shortcomings in policy and practice, but now that their impacts have been registered by managers and policy makers those gaps can be addressed. Although partnership with CAGs is one of many possible instruments that could be employed to achieve effective participation between authorities and local communities, as soon as a CAG starts to achieve its objectives its campaigning power and membership interest can diminish. Ultimately, they can become victims of their own success. By this, it can be suggested that the management authorities, and, particularly the EA continue to develop effective, transparent and sustainable partnership networks with the communities that have been unified by CAGs and especially with successive advisory groups e.g. Creed et al. [61] that can build in a more consensual manner on the changes instigated by the interaction of CAGs in the SMP process.

\section{Acknowledgements}

Thank you to all of those CAG members who participated in this study and particularly to those CAG co-ordinators who made questionnaire arrangements, hosted visits and answered interview questions, your time and contributions to this research are greatly appreciated. Thanks are also due to those coastal managers and consultants who shared candid and revealing insights of their interactions with CAGs and of the effects of CAGs upon shoreline management. We would like to thank Dr Julia Brown for providing guidance at various stages of the research and Paul Carter for preparation of Figure 1 


\section{References}

1. Johnson, C. L., Priest, S. J. (2008). Flood Risk Management in England: A Changing Landscape of Risk Responsibility? International Journal of Water Resources Development. 24(4) pp. 513-525.

2. Pontee N., and Parsons A. (2010) A review of coastal risk management in the UK. Proceedings of the Institution of Civil Engineers, Maritime Engineering 163(1):31-42.

3. Department for Environment, Food and Rural Affairs (2005) Making Space for Water: Taking Forward a New Government Strategy for Flood \& Coastal Erosion Risk Management. Department for Environment, Food and Rural Affairs, London.

4. Department for Environment, Food and Rural Affairs (2011). Understanding the risks, empowering communities, building resilience. Department for Environment, Food and Rural Affairs, London.

5. Cooper, N., Bray, M., Carter, D. and Barber, P. (2002). Shoreline Management Plans: a national review and engineering perspective. Proceedings of the Institution of Civil Engineers, Water and Maritime Engineering, 154 (3), 221-228.

6. Pontee, N. and Parsons, A. (2012). Adaptation as part of sustainable shoreline management in England and Wales. Proceedings of the Institution of Civil Engineers, Maritime Engineering, 165, 113-130.

7. Ballinger, R. C., and Dodds, W. (2017). Shoreline management plans in England and Wales: A scientific and transparent process?. Marine Policy (in press).

8. Nicholls, R., Townend, I., Bradbury, A., Ramsbottom, D., and Day, S. (2013). Planning for long-term coastal change: Experiences from England and Wales. Ocean Engineering, 71, 3-16.

9. Turner, R., and Luisetti, T. (2014). Toward adaptive management in coastal zones. In G., Bruce, P., Mick, K., Robert, T., Ailbhe (Eds.). Climate Change and the Coast: Building Resilient Communities (pp 417-596). Florida, USA: CRC Press.

10. O’Riordan, T., Ward, R. (1997). Building trust in shoreline management: creating participatory consultation in shoreline management plans. Land Use Policy, 14(4), 257-276.

11. O’Riordan, T., Watkinson, A., Milligan, J. (2006). Living with a changing coastline: Exploring new forms of governance for sustainable coastal futures. Technical report 49. Tyndall Centre for Climate Change Research.

12. Cooper, J. A., McKenna, J. (2008). Social justice in coastal erosion management: The temporal and spatial dimensions. Geoforum, 39(1), 294-306.

13. Simm, J. (2015) Direct action self-help groups in UK flood risk management. (PhD thesis), University of Nottingham.

14. Frew, P. (2012). Adapting to coastal change in north Norfolk, UK. Proceedings of the Institution of Civil Engineers: Maritime Engineering, 165 (3), 131-138.

15. Day, S., O’Riordan, T., Bryson, J., Frew, P., and Young, R. (2015). Many stakeholders, multiple perspectives: Long-term planning for a future coast. In R. Nicholls, R., Dawson and S., Day (Eds.), Broad Scale Coastal Simulation (pp. 299-323). Netherland: Netherlands.

16. Renn, O., Webler, T., and Weidemann. (1995). Fairness and competence in citizen participation - Evaluating models for environmental discourse. Netherlands: Kluwer Academic.

17. Edwards S., Jones P., Nowell, D. (1997). Participation in coastal zone management initiatives: a review and analysis of examples from the UK. Ocean \& Coastal Management, 36, 143-165. 
18. Potts, J. (1999). The non-statutory approach to coastal defence in England and Wales: Coastal Defence Groups and Shoreline Management Plans. Marine Policy, 23(4-5), 479500.

19. Fletcher, S. (2003). Stakeholder representation and the democratic basis of Coastal Partnerships in the UK. Marine Policy, 27, 229-40.

20. Fletcher, S. (2007). Influences on stakeholder representation in participatory coastal management programmes. Ocean and Coastal Management, 50, 314-28.

21. Stojanovic, T., Barker R. (2008). Improving governance through local Coastal Partnerships in the UK. The Geographical Journal, 174: 344-360.

22. Scott, W. (2009). Guidance for Community Adaptation Planning and Engagement (CAPE) on the coast. London: Scott Wilson LTD.

23. Schmidt, L., Gomes, C., Guerreiro, S., and O’Riordan, T. (2014). Are we all on the same boat? The challenge of adaptation facing Portuguese coastal communities: Risk perception, trust-building and genuine participation. Land Use Policy, 38, 355-365.

24. Geaves, L. H., and Penning-Rowsell, E. C. (2016). Flood risk management as a public or a private good, and the implications for stakeholder engagement. Environmental Science \& Policy, 55, 281-291.

25. Moon, J., Flannery, W., and Revez, A. (2017). Discourse and practice of participatory flood risk management in Belfast, UK. Land Use Policy, 63, 408-417.

26. Tebboth, M. (2014) Understanding intractable environmental policy conflicts: the case of the village that would not fall quietly into the sea. The Geographical Journal, 180 (3), 224-235

27. Maloney, W., Jordan, G. and McLaughlin, A. (1994). Interest groups and public policy: the insider/outsider model revisited. Journal of Public Policy. 14(01), 17-38.

28. Merchant, C. (2005). Radical ecology: The search for a livable world. New York: Routledge.

29. Wheaton, B. (2007). Identity, politics, and the beach: Environmental activism in surfers against sewage. Leisure Studies, 26(3), 279-302.

30. Jones, C. R., and Eiser, J. R. (2010). Understanding 'local' opposition to wind development in the UK: How big is a backyard? Energy Policy, 38(6), 3106-3117.

31. Hauck, D. (2015). Not In My Backyard activism and information. In S. Friedrich, K. Andrea, and R. Johannes (Eds.), Political Economy and Instruments of Environmental Politics (pp. 229). Cambridge: MIT Press.

32. Kempton, W., Holland, D. C., Bunting-Howarth, K., Hannan, E., Payne, C. (2001). Local Environmental Groups: A Systematic Enumeration in Two Geographical Areas. Rural Sociology, 66, 557-578.

33. Famuditi, T. (2016) Developing local community participation within shoreline management in England; the role of coastal action groups. (PhD Thesis), Department of Geography, University of Portsmouth.

34. Carter, D., Taussik, J., Bray, M., and Hooke, J. (2000). Regional coastal groups in England and Wales: the way ahead. Periodicum Biologorum, 102(1), 215-220.

35. Poortinga, W. and Pidgeon, N. F. (2003). Public perceptions of risk, science and governance. Norwich: UEA/ MORI.

36. Cundill, G., and Rodela, R. (2012). A review of assertions about the processes and outcomes of social learning in natural resource management. Journal of Environmental Management, 113(1), 7-14.

37. Bush, D., and Hoagland, P. (2016). Public opinion and the environmental, economic and aesthetic impacts of offshore wind. Ocean \& Coastal Management, 120, 70-79.

38. NVCC (nd). National Voice of Coastal Communities website: http://www.nvcc.org.uk/ 
39. Jordan, G., and Maloney, W. (1997). The protest business? Mobilising campaign groups. Manchester: University Press.

40. Devine-Wright, P. (2009). Rethinking NIMBYism: the role of place attachment and place identity in explaining place protective action. Journal of Community and Applied Social Psychology, 19, 426-441.

41. Bell, S., Ward Thompson, C., Findlay, C. Morris, N. Travlou, P., and Montarzino, A. (2003). Nature for people: The importance of green spaces to East Midlands communities. Peterborough: Natural England.

42. Sparrowe, R., Liden, R., Wayne, S., and Kraimer, M. (2001). Social networks and the performance of individuals and groups. Academy of Management Journal, 44(2), 316325.

43. Agyeman, J, and Evans, B (2004) 'Just sustainability': The emerging discourse of environmental justice in Britain? Geographical Journal, 170, 155-164.

44. Inglehart, R., and Catterberg, G. (2002). Trends in political action: The developmental trend and the post-honeymoon decline. International Journal of Comparative Sociology, 43(3-5), 300-316.

45. Lubet, S. (2001). Judicial campaign conduct committees: Some reservations about an elegant solution. Indiana Law Review. 35(1), 807-881.

46. Dür, A., \& Mateo, G. (2013). Gaining access or going public? Interest group strategies in five European countries. European Journal of Political Research, 52(5), 660-686.

47. Gil de Zúñiga, H., Jung, N., \& Valenzuela, S. (2012). Social media use for news and individuals' social capital, civic engagement and political participation. Journal of Computer-Mediated Communication, 17(3), 319-336.

48. Leizerov, S. (2000). Privacy Advocacy Groups Versus Intel: A Case study of how social movements are tactically using the internet to fight corporations. Social Science Computer Review, 18(4), 461-483.

49. Taylor, M., Kent, M., and White, W. (2001). How activist organizations are using the Internet to build relationships. Public Relations Review, 27(3), 263-284.

50. Lelieveldt, H. (2014). Lobbying Governments or Corporations? A Comparative Case Study of Old and New Tactics to Improve Factory Farming in the Netherlands.

51. Chadwick, A., and Dennis, J. (2017). Social media, professional media and mobilisation in contemporary Britain: Explaining the strengths and weaknesses of the Citizens’ Movement 38 Degrees. Political Studies, 65(1), 42-60.

52. Lilleker, D., and Jackson, N. (2013). Political campaigning, elections and the Internet: Comparing the US, UK, France and Germany (Vol. 4). London: Routledge.

53. Lovejoy, K., and Saxton, G. D. (2012). Information, community, and action: How nonprofit organizations use social media. Journal of Computer-Mediated Communication, 17(3), 337-353.

54. Poell, T., and Borra, E. (2012). Twitter, YouTube, and Flickr as platforms of alternative journalism: The social media account of the 2010 Toronto G20 protests. Journalism, 13(6), 695-713.

55. Merry, M. K. (2014). Broadcast versus interaction: environmental groups' use of Twitter. Journal of Information Technology \& Politics, 11(3), 329-344.

56. Jordan, G., and Maloney, W. (1998). Manipulating membership: supply-side influences on group size. British Journal of Political Science, 28(2), 389-409.

57. Bosso, C. J. (2003). Rethinking the concept of membership in nature advocacy organizations. Policy Studies Journal, 31(3), 397-411.

58. Department for Environment, Food and Rural Affairs (2008). Coastal groups in England - the Environment Agency strategic overview of sea flooding and coastal erosion risk management. Retrieved from the Defra website: 
ttp://www.defra.gov.uk/environment/flooding/documents/who/cgreport.pdf

59. Department for Environment, Food and Rural Affairs. (2012). Coastal Change Pathfinder Review. Report PB 13720, Department for Environment, Food and Rural Affairs, London.

60. Environment Agency, (2008) Pagham to East Head Coastal Defence Strategy. Environment Agency.

61. Creed, R., Baily, B., Potts, J., Bray, M., \& Austin, R. (2018). Moving towards sustainable coasts: A critical evaluation of a stakeholder engagement group in successfully delivering the mechanism of adaptive management. Marine Policy (in Press).

62. Beierle, T. C., and Cayford, J. (2001). Evaluating dispute resolution as an approach to public participation. Washington, DC: Resources for the Future.

63. Creighton, J. (2005). The public participation handbook: Making better decisions through citizen involvement. San Francisco: Jossey Bass.

64. Tompkins, E., Adger, W., Boyd, E., Nicholson-Cole, S., Weatherhead, K., and Arnell, N. (2010). Observed adaptation to climate change: UK evidence of transition to a welladapting society. Global Environmental Change, 20(4), 627-635.

65. Keen, M., Brown, V., and Dyball, R. (2005). Social learning in environmental management: towards sustainable future, Oxford: Earthscan.

66. Tritter, J., and McCallum, A. (2006). The snakes and ladders of user involvement: moving beyond Arnstein. Health Policy, 76(2), 156-168. 